\title{
STUDIES OF FOOD QUALITY AND PREFERENCE: THE CONTRIBUTION OF ROSE MARIE PANGBORN
}

\author{
Adam Drewnowski \\ Human Nutrition Program, School of Public Health, The University of Michigan, Ann Arbor, MI 48109-2029, USA
}

(Paper presented at 'Advances in Sensory Food Science', Rose Marie Pangborn

Memorial Symposium, 2-6 August 1992, Järuenpä̈, Finland)

\section{ABSTRACT}

Modern sensory analysis of foods and the evaluation of food preferences have been greatly influenced by the innovative research and teaching of Rose Marie Pangborn. Her work has also had a major impact on the study of dietary behaviors and the regulation of food intake. Among her many research contributions were the use of complex stimuli in sensory evaluation studies, the focus on individual differences in hedonic response profiles, and the study of attitudes and beliefs as potential determinants of food acceptance.

Keywords: Complex stimuli; hedonic profiles; individual differences; attitudes and beliefs.

\section{INTRODUCTION}

Modern sensory analysis of foods and the evaluation of food acceptance have been greatly influenced by the research and teaching of Professor Rose Marie Pangborn. In the course of a research career that spanned a period of over 30 years, Rose Marie published almost 200 papers on the perception of taste, smell, and texture, and on selected aspects of food preference and diet choice.

Rose Marie Pangborn was one of the early leaders in the scientific assessment of consumer preferences for foods and beverages. She was co-author, with Professors Amerine and Roessler, of the classic textbook Principles of Sensory Evaluation of Foods (Amerine et al., 1965). The sensory evaluation course that she taught for many years at the University of California, Davis, was justifiably famous and remains a model of its kind.

It is a fitting tribute to Rose Marie's memory that so many of her former students have risen to prominence in academic life and in the food industry. This sympo-

(C) 1993 Elsevier Science Publishers Ltd 0950-3293/93/ $\$ 06.00$ sium features presentations by distinguished experts, many of whom were Rose Marie's students, colleagues, and friends.

The wide range of topics included in the symposium provides a further indication of the breadth of Rose Marie Pangborn's research interests and the extent of her influence on the area of food science and technology. However, we should also remember that her contributions extend well beyond the core area of sensory evaluation of foods into the science of human behavior. Rose Marie devoted much attention to the study of food selection and the diverse antecedents of food choice. Her meticulous work was much admired by researchers in human nutrition, and came to influence numerous studies on the regulation of food intake in humans.

The work of Rose Marie Pangborn has helped to establish the central role of taste as the key determinant of food acceptance and therefore diet selection. She wrote as early as 1959 that 'the sense of taste and food preferences are undoubtedly influenced by body chemistry. However, little is known about the psychologic, physiologic and chemical interactions which regulate the sense of taste and consequent food selection' (Pangborn, 1959). More than 30 years later, the relationship between taste responsiveness and food selection remains an important area of scientific inquiry.

Rose Marie's contributions to the study of taste responsiveness and food acceptance can be divided into three main areas. The first major innovation that distinguished her work from other studies in taste psychophysics was her use of complex stimuli in sensory evaluation studies. She was among the first scientists to bridge the gap between model systems and real foods in using complex stimuli in the study of sweetness interactions with color or flavor, and in the determination of food preference. Her earliest publications dealt with the sweetness of canned apricots and consumer preferences for vanilla ice cream (Valdes \& Roessler, 1956; Pangborn et al., 1957).

Her second major contribution lay in the recognition that hedonic response profiles differ greatly among individuals (Pangborn, 1970). The study of individual variability in taste preference was one research 
topic that she reverted to often in the course of her career. In searching for a link between sensory responsiveness and nutritional status, Rose Marie examined sweetness preferences in relation to body weight, and addressed food preferences and eating patterns of obese patients as a function of intcrnal states, weight history, and dieting behaviors (Pangborn \& Simone, 1958).

The third major area of nutrition research concerned the determinants of food acceptance, and the disparities in food choice across individuals. While taste preferences may be a key factor influencing food selection, other more personal and idiosyncratic variables also play a part. Rose Marie's studies in this area addressed the role of personal traits in determining food acceptance, and the role of diet-related attitudes on behavior (Pangborn, 1987). This important work, merging strategies for behavioral change with sensory response to foods, is becoming increasingly relevant in our attempts to change the dietary behaviors of individuals and communities.

These three main aspects of Rose Marie Pangborn's work on taste and food acceptance are summarized below. There are several instances where current studies in a given area have their antecedents in one of her papers published two or even three decades ago. Tracking and documenting some of these influences is one purpose of this review.

\section{THE USE OF COMPLEX STIMULI}

'In the mind of the layman', wrote Rose Marie Pangborn in 1958, 'sugar and sweets are "fattening", and most overweight individuals have a "sweet tooth", (Pangborn \& Simone, 1958). At that time, most studies on food acceptance equated palatability with sweet taste. However, while sucrose solutions in distilled water remained for many years the sensory stimuli of choice, Rose Marie Pangborn conducted her studies using complex food-like stimuli, including canned apricots, pears, peaches, and vanilla ice cream (Pangborn \& Simone, 1958; Pangborn, 1959).

One of her first published studies on body size and sweetness preference (Pangborn \& Simone, 1958) was conducted at the 1956 California State Fair. Apricots, pears, peaches, and ice cream differing in sugar content were evaluated during four consumer surveys by a total of 12505 people. Both the hedonic preference scale and the paired-comparison method were used to establish consumer preferences. In a typically thorough fashion, each consumer's age, sex, height, and weight, were used to classify him or her into one of three groups: underweight, normal weight, or overweight.

The study showed that overall liking for the sweet stimuli was unaffected by body size. As shown in Fig. 1, the mean hedonic response profile for vanilla ice cream followed an inverted-U curve. There were no differences in preference as a function of overweight, suggesting that the obese 'sweet tooth' was most likely a myth.

As often happens with classic research, these 1958 findings were ignored for more than a decade. The field reverted to the study of sucrose solutions in water, and several reports claimed that obese individuals, whether hungry or satiated, liked palatable sweet solutions better than did normal-weight controls. Enhanced responsiveness to sweet taste was variously thought to reflect long-term energy deprivation status (Cabanac \& Duclaux, 1973), or the distance from the physiological set-point of body weight (Rodin, 1975). Reputed liking for sweet taste among the obese was further taken as evidence that obese individuals were more attuned to such 'external' factors as palatability, as opposed to the 'internal' sensations of hunger and satiety.

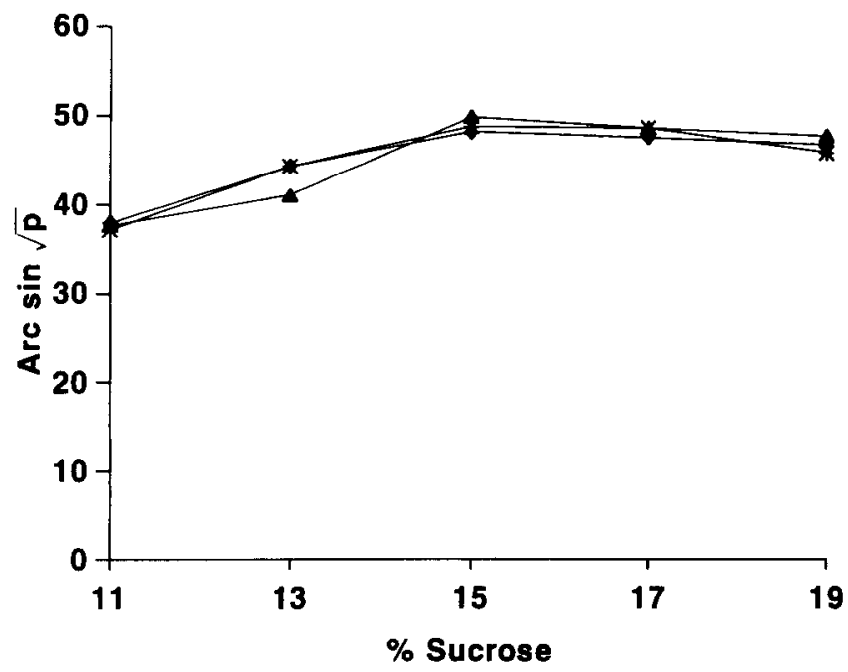

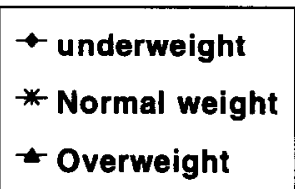

FIG. 1. Preferences for sweetness in vanilla ice cream as a function of body weight. Preference ratings are expressed as arc sine transform. Data from Pangborn \& Simone (1958). 
It was not until the late 1970 s that the scientific consensus regarding taste preferences in human obesity began to emerge. For the most part, scientists have accepted the fact that there was no consistent relationship between the degree of overweight and sensory preference for sucrose solutions, sweetened fruitflavored beverage (Kool-Aid), or sweetened lemonade. Rose Marie Pangborn returned to this issue in a 1980 paper (Witherly et al., 1980), showing that individual variability in hedonic preferences for varying concentration of sugar in lemonade overwhelmed any potential differences between obese and normal-weight subjects.

While preferences for sweet solutions were not influenced by body weight (Drewnowski, 1987), hedonic preferences for more complex sugar/fat mixtures did vary with the respondents' weight status. Specifically, preferences for fat in foods discriminated between overweight and underweight women (Drewnowski \& Greenwood, 1983). These studies on human preferences for high-fat foods were directly influenced by the work of Rose Marie Pangborn. Early on, she recognized the contribution of dietary fats to the perception of food texture and their contribution to food acceptability. Sensory perception of fat in milk was the subject. of several early papers (Pangborn \& Dunkley, 1964a). In a classic sensory evaluation mode, these studies, conducted with highly trained panels, employed such refinements as nose clips and a room illuminated with dim red light (Pangborn \& Dunkley, 1964b).

Up to that point, few studies had systematically addressed the sensory perception of fat in foods. Although the flavor of dairy products has concerned researchers for many years, their textural properties have received little research attention. Pangborn's early studies showed that the sensory assessment of fats in milk largely depended on the evaluation of mouthfeel and texture, and to a lesser degree on olfaction (Pangborn \& Dunkley, 1964a,b). For liquid dairy products, where fat is contained in emulsified globules, the perception of 'fatness' was believed to be guided by the perception of stimulus smoothness, thickness, or viscosity. In fact, the standard viscosity scale developed as part of the General Foods Texture Profile used as reference points foods such as cream, mayonnaise or sweetcned condensed milk containing different amounts of fat (Brandt et al., 1963). More recent studies on liquid dairy products have suggested that mouthfeel attributes of thickness, smoothness, and creaminess are all closely linked to the stimulus fat content (Kokini et al., 1977; Cussler et al., 1979; Cooper, 1987; Drewnowski, 1987a).

In our studies on body weight and taste responsiveness, we used as stimuli 20 sweetened milk products ranging from skim milk to heavy cream, and of varying sugar and fat content (Drewnowski \& Greenwood, 1983; Drewnowski et al., 1985, 1987). Sugar and fat levels were orthogonally varied, and the stimuli, chilled

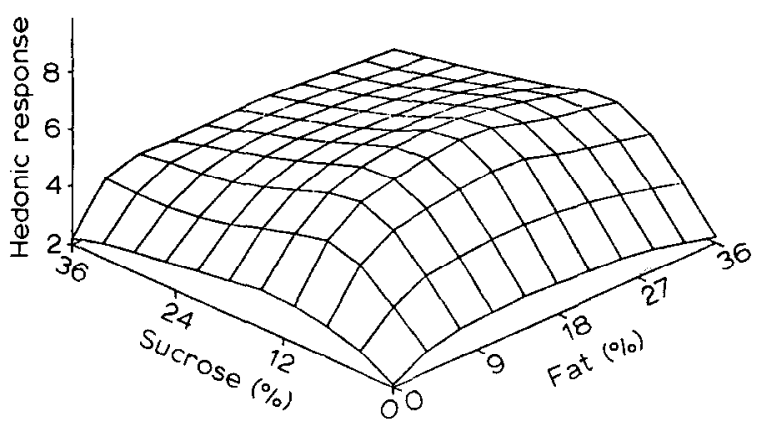

FIG. 2. Three-dimensional representation of the hedonic response surface as a function of stimulus sugar and fat content. Data from Kaye (1986).

to $5^{\circ} \mathrm{C}$, were presented to subjects in plastic cups for sensory and hedonic evaluations.

Hedonic response profiles were strongly interactive. Typically, prefcrence ratings for sweetness in liquid foods show an optimum point or 'breakpoint' at around 8-10\% sucrose (Moskowitz et al., 1974). In our study, the two-dimensional preference response depended on the proportions of the two ingredients, sugar and fat. The shape of the hedonic response was then modeled using a computer modeling procedure known as the Response Surface Methodology (Drewnowski et al., 1985, 1987). While unsweetened dairy products, or sugar in skim milk, were only marginally acceptable, normal-weight subjects gave high preference ratings to stimuli containing $8 \%$ sugar and approximately $20 \%$ fat (Drewnowski \& Greenwood, 1983). A replication of that study conducted with normalweight students in Rose Marie's laboratory (Kaye, 1986) confirmed that maximal hedonic preferences were obtained for mixtures containing $9 \%$ sucrose and $20 \%$ fat. A three-dimensional representation of the mean hedonic response is shown in Fig. 2.

Further studies were conducted with women subjects across a wide range of body weights (Drewnowski et al., 1985,1987 ). Massively obese women patients selected stimuli that were relatively low in sugar $(4 \% \mathrm{wt} / \mathrm{wt})$ but were rich in fat $(>30 \% \mathrm{wt} / \mathrm{wt})$. In contrast, emaciated anorectic women liked intense sweetness (15\% sugar $\mathrm{wt} / \mathrm{wt}$ ), but showed a dislike, if not an aversion, to the oral sensation of dairy fat.

The relationship between sensory preferences for fat and the degree of overweight suggested that fat, as opposed to sugar, may play a role in the development and maintenance of the obese state. Since that time, other studies have examined preferences for fat and sugar in such model systems as cake frostings, cream cheese, or ice cream (Drewnowski, 1987b). The one attempt to examine the sensory interactions between fat and salt in a dill-flavored yogurt dip was again made by Rose Marie Pangborn (Pangborn, 1988). Most recently, studies using fat in mashed potatoes and scrambled eggs have confirmed that sensory preferences for fat in 
TABLE 1. Optimal Preferences for Sugar and Fat in Sweetened Milk Drinks as a Function of Successful Weight Loss in Obese Women Patients

\begin{tabular}{lccc}
\hline \multicolumn{1}{c}{ Group } & Month & \% Sucrose & \% Fat \\
\hline Successful & 0 & $27 \cdot 0$ & $22 \cdot 8$ \\
& 3 & $19 \cdot 4$ & $16 \cdot 0$ \\
& 6 & $19 \cdot 3$ & $18 \cdot 0$ \\
Unsuccessful & 0 & $21 \cdot 1$ & $21 \cdot 2$ \\
& 3 & $20 \cdot 6$ & 21.4 \\
& 6 & 23.0 & 22.4 \\
\hline
\end{tabular}

Data from Pangborn (1987).

foods are directly linked to the percentage of the subjects' body fat (Mela \& Sacchetti, 1991).

Given the current emphasis on the role of dietary fat in human obesity, much attention has been devoted to the question whether sensory preferences for fat change as a function of dieting and weight loss. Rose Marie's work suggested that sensory preferences for sugar and fat may distinguish between successful and unsuccessful weight loss. Using a population of obese women patients at an obesity clinic at Davis, Pangborn (1987) observed that weight loss was associated with altered sensory preferences for sugar and fat. As shown in Table 1, lower breakpoints for sugar and fat were obtained for successful (though not for unsuccessful) weight-loss patients in a model system of sweetened dairy products.

Rose Marie's sensory evaluation studies employed both model systems and real foods. She made use of aqueous solutions in the study of sweetness interactions with other basic tastes and other food attributes, such as flavor, or color (Pangborn, 1960). This work was subsequently extended to the study of sweetness interactions with stimulus viscosity and texture. In later years, the study of model systems included time-course analysis of viscosity, sweetness, and flavor perception.

\section{THE STUDY OF INDIVIDUAL DIFFERENCES}

One of Rose Marie Pangborn's earliest papers addressed taste responsiveness as a function of gender and motivational state (Pangborn, 1959). No relationship was observed between degree of hunger and sweetness preferences in canned cling peaches as evaluated by 11456 consumers at the 1957 California State Fair. Similar results were obtained from a highly trained laboratory panel of eight judges tasting sweetened apricot nectar under fasting versus non-fasting conditions (see Fig. 3).

Even so, considerable efforts during the 1970 s were devoted to showing that hunger and satiety had a major impact on sensory preferences for sweet taste. While normal-weight subjects reduced their preferences for sucrose after drinking a sweet glucose solution, this phenomenon, dubbed satiety aversion to sucrose, was reportedly lacking in anorectic women, dieting lean subjects, or obese patients below their physiological setpoint (Cabanac \& Duclaux, 1970).

However, these findings were far from robust, and there was much variability across individuals. While some subjects showed a reduced response to sweetness following a sweet preload, others did not (Drewnowski, $1987 a$ ). Furthermore, a shift in sweet taste preference, even when obtained, did not appear to be linked to the body weight of the respondents. An aversion to sweet taste could be produced using a sweet but non-caloric cyclamate solution (Wooley et al., 1972). On the other hand, caloric manipulations such as dinner, lunch, or overnight fasting generally failed to influence hedonic preferences for sweet taste. It appears that preferences for sweet taste are selectively reduced not by calories, but by a prior exposure to sweetness; a phenomenon more in line with the sensory specific satiety model than with the original notion of satiety aversion to sucrose and negative aliesthesia (Cabanac \& Duclaux,

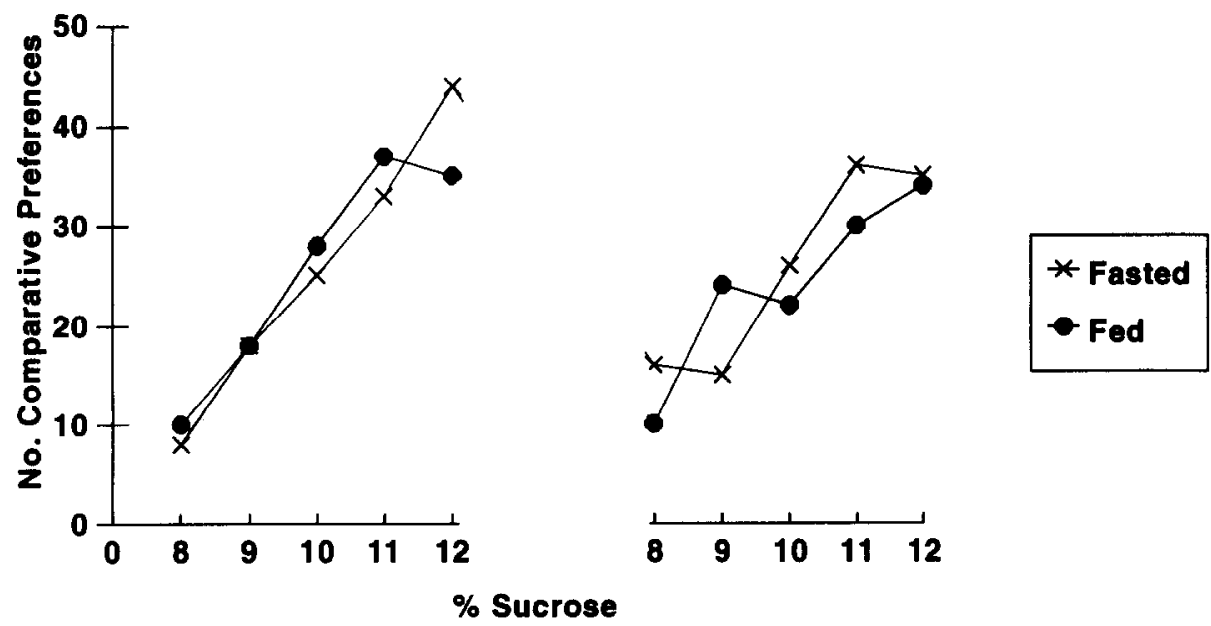

FIG. 3. Preferences for sweetness in apricot nectar for men (left panel) and women (right panel) as a function of fasting status. Data from Pangborn (1959). 
1970). Again, the current scientific consensus is very much in line with Pangborn's original 1959 finding.

Individual variability in taste preferences for sweet solutions among normal-weight subjects is also a wellestablished phenomenon. Pfaffman (1961) had initially reported a modal response of increasing liking for sweet solutions among normal-weight subjects, with a minority of subjects reporting a dislike. The inverted Ushape of the hedonic response to sweetness is therefore likely to be a composite of widely different individual responses. Pangborn (1970) similarly distinguished between those subjects who liked solutions of increasing sweetness intensity and those who did not.

Different response types have also been observed among obese and non-obese subjects. Thompson et al. (1976) classified individuals on the basis of their hedonic response as a function of increasing sweetness concentration. Type I response was characterized by a rise and decline (U-shape), while Type II was a rise followed by a plateau. Most obese subjects in that study were classified as Type I respondents, showing a sharp decline at the most intense sweetness concentrations (Thompson et al., 1976).

Witherly et al. (1980) distinguished four separate types of response: in addition to Types I and II, Type III represented a monotonic decline in preference, while Type IV represented no systematic change with increasing sweetness concentration. The different types of response were observed among obese and lean subjects alike, and individual variability of response was greater than any obese/lean subject differences (Pangborn, 1981).

The use of complex fat-containing stimuli poses further problems for sensory evaluation research. Unlike preferences for sucrose solutions in water or lemonade, preference for dietary fats are likely to be not only idiosyncratic, but also system-specific. For example, high acceptability of rich, high-fat ice cream need not imply liking for greasy hamburgers. Unlike sugar, which is commonly viewed as a food additive, fat is often perceived as an integral part of the food itself, and preferences for dietary fats are likely to vary between one food system and another.

Studies on the role of dietary fats in human obesity have therefore attempted to evaluate a wider range of foods, and to link hedonic ratings, where possible, to self-reported food preferences and to actual measures of food intake (Pangborn et al., 1985). Other studies have focused on the role of diet-related attitudes and beliefs in influencing food selection and diet choice.

\section{BEHAVIORAL MODELS OF FOOD SELECTION}

Food habits are mediated by familial, cultural, and socioeconomic factors as well as by the sensory quality of individual foods (Pangborn, 1987). Personal traits and health-related attitudes may also exert a profound influence on food preferences and diet selection. Attitudes toward such health-sensitive food ingredients as fat, sugar and salt, in particular, are liable to influence food preferences and food choice (Shepherd \& Stockley, 1985).

In her later work, Rose Marie Pangborn focused on the behavioral models of food choice and the relationship between personal traits and attitudes and the acceptance of food attributes. This work combined such areas as the relationship between personality traits and preferences for sweet and salty beverages, and the relation of selected attitudes to dietary intake of sugar and fat (Pangborn \& Giovanni, 1984; Stone \& Pangborn, 1990). Other studies examined the relationship between the health/nutrition locus of control and preferences for fat, sugar, and salt.

These studies used a variety of behavioral models, notably the Fishbein and Ajzen model of reasoned action, to predict the consumption of selected sweet, salty, or fat-containing foods (Tuorila \& Pangborn, 1988 a, 1988b). The model uses such constructs as attitudes and beliefs, as well as subjective norms in predicting behavioral intent and hence actual behavior. While the model had been previously applied to diverse health behaviors, including smoking cessation and weight loss, its application to the study of food-related behaviors represented a major innovation.

This is a very important and relatively new area of research. The present research emphasis in public health nutrition is on changing dietary behavior of communities (Henderson et al., 1992). While the connection between diet, nutrition, and chronic disease risk is wellestablished (Surgeon General's Report, 1988), there is a shortage of ideas as to how to implement dietary guidelines on a population-wide basis.

The current dietary recommendations for the American public are to replace meats and full-fat dairy products with grain products, vegetables and fruits (Surgeon General's Report, 1988). American consumers are said to be increasingly receptive to lowcalorie food products as they become more concerned with issues of nutrition and health. However, the available data on food consumption do not support this view (Putler \& Frazao, 1991).

In 1985, American women ate less meat and fewer full-fat dairy products than in 1977. Education and income correlated with greater nutritional awareness and better compliance with hcalthy dicts. The greatest decline in the consumption of meat, whole milk and eggs was observed among the most highly educated women. However, these women also consumed more cheese, frozen desserts, baked goods, table fats, and salad dressings. As a result, total fat intake ( $37 \%$ of daily calories) was independent of both education and income. In contrast, according to some USDA data, there was an 
overall decline in the consumption of fruits and vegetables, with the greatest drop reported by low-income women (Putler \& Frazao, 1991).

These data pose a challenge to nutrition professionals and suggest a need for further collaboration between nutrition and the behavioral sciences in the design of strategies for dietary change. Existing data suggest that many consumers have learned to trade sources of dietary fat, replacing one source of fat with another. We need more studies on the determinants of food acceptance that examine the interaction between sensory attributes of foods and the consumers' beliefs, attitudes and behaviors.

\section{CONCLUSIONS}

Rose Marie Pangborn's achievements in the area of sensory evaluation of foods and beverages are wellknown to anyone familiar with food science and technology. However, her teaching and research wcrc also influential in other areas of basic science, including nutrition and the study of human behavior. She has made important contributions to the field of regulation of food intake in humans, and she has pioneered many approaches and techniques that are now taken for granted. Her influence continues. Rose Marie Pangborn was an original thinker and researcher, a valued colleague and a mentor to several generations of students. She is greatly missed.

\section{REFERENCES}

Amerine, M. A., Pangborn, R. M. \& Roessler, E. B. (1965). Principles of Sensory Evaluation of Foods. Academic Press, New York, $602 \mathrm{pp}$.

Brandt, M. A., Skinner, E. Z. \& Coleman, J. A. (1963). Texture profile method. J. Food Sci., 28, 404-9.

Cabanac, M. \& Duclaux, R. (1970). Obesity: Absence of satiety aversion to sucrose. Science, 168, 496-7.

Cabanac, M., Duclaux, R. (1973). Alliesthesie olfacto-gustative et prise alimentaire chez l'homme. J. Physiol. (Paris), 66, 113-35.

Cooper, H. R. (1987). Texture in dairy products and its sensory evaluation. In Food Texture, ed. H. R. Moskowitz. Marcel Dekker, New York.

Cussler, E. L., Kokini, J. L., Weinheimer, R. L. \& Moskowitz, H. R. (1979). Food texture in the mouth. Food Technol., 33, 89-92.

Drewnowski, A. (1987a). Sweetness and obesity. In Sweetness, ed. J. Dobbing. Springer-Verlag, New York, pp. 177-92.

Drewnowski, A. (1987b). Fats and food texture: Sensury and hedonic evaluations. In Food Texture, ed. H. R. Moskowitz. Marcel Dekker, New York. pp. 217-50.

Drewnowski, A. \& Greenwood, M. R. C. (1983). Cream and sugar: Human preferences for high-fat foods. Physiology $\mathcal{E}^{\circ}$ Behavior, 30, 629-33.
Drewnowski, A., Brunzell, J. D., Sande, K, Iverius, P. H. \& Greenwood, M. R. C. (1985). Sweet tooth reconsidered: Taste preferences in human obesity. Physiology $\mathcal{F}^{\circ}$ Behavior, 3, 617-22.

Drewnowski, A., Halmi, K. A., Pierce, B., Gibbs, J. \& Smith, G. P. (1987). Taste and eating disorders. Am. J. Clin. Nutr., 46, 442-50.

Henderson, M. M., Bowen, D. J. \& DeRoos, K. K. (1992). Promoting dietary change in communities: applying existing models of dietary change to population-based interventions. Cancer Prevention Research Program, Fred Hutchinson Cancer Research Center, Seattle, WA.

Kaye, A. (1986). Relation of weight loss, food intake, and locus of control by obese and normal-weight women to degree of liking for fat, sucrose, and sodium chloride. MS thesis, University of California, Davis.

Kokini, J. L., Kaldane, J. B. \& Cussler, E. L. (1977). Liquid texture perceived in the mouth. J. Texture Studies, 8, 195-218.

Mela, D. J. \& Sacchetti, D. A. (1991). Sensory preferences for fats: relationships with diet and body composition. Am.J. Clin. Nutr., 53, 908-15.

Moskowitz, H. R., Kluter, R. A., Westerling, J. \& Jacobs, H. L. (1974). Sugar sweetness and pleasantness: evidence for different psychophysical laws. Science, 184, 583-5.

Pangborn, R. M. (1959). Influence of hunger on sweetness preference and taste thresholds. Am. J. Clin Nutr., 7, 2807.

Pangborn, R. M. (1960). Influence of color on the discrimination of sweetness. Am. J. Psychology, 73, 229-38.

Pangborn, R. M. (1970). Individual variation in affective responses to taste stimuli. Psychonomic Science, 21 (2), 125-6.

Pangborn, R. M. (1981). Individuality in response to sensory stimuli. In Criteria of Food Acceptance: How Man Chooses What He Eats, ed. J. Solms \& R. L. Hall. Foster-Verlag, Zurich, pp. 117-219.

Pangborn, R. M. (1987). Relationship of personal traits and attitudes to acceptance of food attributes. In Food Acceptance and Nutrition, ed. J Solms, D. A. Booth, R. M. Pangborn \& O. Raunhardt. Academic Press, London, pp. 353-70.

Pangborn, R. M. (1988). Sensory attributes and acceptance of fat, sugar, and salt in dairy products. In Food Acceptability, ed. D. M. H. Thomson. Elsevier Applied Science, London, pp. 413-29.

Pangborn, R. M. \& Dunkley, W. L. (1964a). Sensory discrimination of fat and solids-not-fat in milk. J. Dairy Sci., 47, 719-26.

Pangborn, R. M. \& Dunkley, W. L. (1964b). Difference-preference evaluation of milk by trained judges. J. Dairy $S c i ., 47$, 1414-16.

Pangborn, R. M. \& Giovanni, M. E. (1984). Dietary intake of sweet foods and of dairy fats and resultant gustatory responses to sugar in lemonade and to fat in milk. Appetite, $\mathbf{5}$, 317-27.

Pangborn, R. M. \& Simone, M. (1958). Body size and sweetness preference. J. Am. Dietetic Assoc., 34, 924-8.

Pangborn, R. M., Simone, M. \& Nickerson, T. A. (1957). The influence of sugar in ice cream. I. Consumer preference for vanilla ice cream. Food Technol., 11, 679-82.

Pangborn, R. M., Bos, K. F. O. \&c Stern, J. S. (1985). Dietary fat intake and taste responses to fat in milk by under-, normal- and over-weight women. Appetite, 6, 25-40.

Pfaffman, C. (1961). The sensory and motivating properties 
of the sense of taste. In Nebraska Symposium on Motivation, cd. M. R. Jonc. University of Nebraska Press, Nebraska, pp. 71-110.

Putler, D. \& Frazao, E. (1991). Diet/health concerns about fat intake. National Food Review, 1, 16-18.

Rodin, J. (1975). Effects of obesity and set point on taste responsiveness and ingestion in humans. $J$. Comparative Physiol. Psychology, 89, 1003-9.

Shepherd, R. \& Stockley, L. (1985). Fat consumption and attitudes towards food with a high-fat content. Human Nutrition: Applied Nutrition, 39A, 431-42.

Stone, L. J. \& Pangborn, R. M. (1990). Preferences and intake measures of salt and sugar, and their relation to personality traits. Appetite, 15, 63-79.

Surgeon General's Report on Nutrition and Health (1988). DHHS (PHS) Publ. no. 88-50210. US Govt Printing Office, Washington, D.C.

Thompson, D. A., Moskowitz, H. R. \& Campbcll, R. (1976).
Effects of body weight and food intake on pleasantness ratings for a sweet stimulus. J. Appl. Psychology, 41, 77-83.

Tuorila, H. \& Pangborn, R. M. (1988a). Behavioral models in the prediction of consumption of selected sweet, salty and fatty foods. In Food Acceptability, ed. D. M. H. Thomson. Elsevier Applied Science, London, pp. 267-79.

Tuorila, H. \& Pangborn, R. M. (1988b). Prediction of reported consumption of selected fat-containing foods. Appetite, 11, 81-95.

Valdes, R. M. \& Roessler, E. B. (1956). Consumer survey on the dessert quality of canned apricots. Food Technol., 10, $481-6$.

Witherly, S. A., Pangborn, R. M. \& Stern, J. S. (1980). Gustatory responses and eating duration of obese and lean adults. Appetite, 1, 53-63.

Wooley, O. W., Wooley, S. C. \& Dunham, R. B. (1972). Calories and sweet taste: effects of sucrose preference in the obese and non-obese. Physiology $\mathcal{E}$ Behavior, 79, 765-8. 